\title{
Cooperativismo e reciclagem de resíduos sólidos: uma reflexão a partir da psicanálise de grupos
}

\author{
Carlos Alberto Pegolo da Gama ${ }^{\mathrm{I}}$ e Mirna Yamazato Koda ${ }^{\mathrm{II}}$ \\ ${ }^{\mathrm{I}}$ Universidade do Vale do Sapucaí \\ ${ }^{\text {II } U n i v e r s i d a d e ~ S a ̃ o ~ F r a n c i s c o ~}$
}

\begin{abstract}
O presente artigo tem como objetivo refletir a respeito de uma intervenção da área de psicologia comunitária em uma cooperativa de reciclagem de resíduos sólidos. A intervenção inseriu-se em um projeto mais amplo, que envolvia as áreas de engenharia, administração e pró-reitoria comunitária. A intervenção da psicologia consistiu em entrevistas individuais, apoio psicossocial aos cooperados, realização de um grupo operativo que envolvia todos os cooperados e o acompanhamento das assembleias gerais da cooperativa. $\mathrm{O}$ grupo operativo tinha como objetivo abordar as dificuldades vividas no cotidiano de trabalho do grupo em questão. Realizamos a análise dessa intervenção tendo como referencial teórico a psicanálise de grupos. Levantamos a hipótese de que o significante "lixo" poderia funcionar como um organizador psíquico grupal. Haveria uma oscilação no grupo entre a representação do lixo (inútil, sujo, indesejável) e a representação dos resíduos sólidos e material reciclável (recurso útil, cuidado ambiental, ecologia). Tal hipótese nos levou a desenvolver intervenções que pudessem, a partir de ações concretas junto ao grupo, explicitar e integrar esses aspectos dissociados: por um lado, a vivência de grande desvalorização e desamparo, por outro, uma potência de crescimento, organização e desenvolvimento.
\end{abstract}

Palavras-chave: Cooperativismo, Psicologia social, Psicanálise de grupos, Reciclagem de resíduos sólidos.

Cooperativism and recycling of solid wastes: a reflection based on group psychoanalysis

This article aims to reflect on an intervention in community psychology in a cooperative recycling of solid wastes. The intervention was part of a broader project that involved the engineering, administration and pro-rectory of community. The psychology intervention consisted of individual interviews, psychosocial support to members, execution of an operative group involving all cooperates and monitoring of the general assembly of the cooperative. The operative group had intended to address difficulties experienced in daily work life of the group in question. We performed the analysis of this intervention utilizing as theoretical framework the psychoanalysis of groups. We hypothesize that the significant "garbage" could working as a psychic group organizer. There would be an oscillation in the group between the representation of garbage (useless, dirty, undesirable) and the representation of the solid wastes and recyclable materials (usefull resource, environmental care, ecology). Such hypothesis led us to develop interventions that could, from concrete actions with the group, explicit and integrate these dissociated aspects: on one hand, the experience of large devaluation and helplessness, on the other, power of growth, organization and development.

Keywords: Cooperativism, Social psychology, Groups psychoanalysis, Recycling of solid wastes.

\section{Introdução}

s discussões contemporâneas sobre o cooperativismo estão inseridas em um contexto mais
finplo de transformações da economia, que incluem a globalização, a especulação
tona questionamentos acerca dos modos de produção e das relações de trabalho tradicionais.
Faz-se necessária aí uma mobilização no sentido de construir alternativas para a marginalização
social de grupos cada vez mais numerosos. Vemos, em diversos setores, a busca de saídas
comunitárias para tal conjuntura. 
A constituição de cooperativas e o projeto da economia solidária (Singer, 2002) têm surgido como respostas à retração do mercado de trabalho, contrapondo-se ao modelo vigente de produção e de acúmulo de capital. A formação de cooperativas envolve problemáticas de diversas ordens, dentre elas há aquelas relacionadas à dinâmica tradicional estabelecida no trabalho e as relações de poder aí existentes, assim como a representação que o sujeito possui sobre a questão do trabalho. O modelo tradicional propicia o estabelecimento de processos grupais que se organizam prioritariamente de maneira verticalizada baseado na figura do patrão. No entanto, a montagem de uma cooperativa necessitaria o estabelecimento de uma organização mais horizontalizada, na qual o poder estaria distribuído entre os cooperados e as decisões seriam baseadas no consenso grupal.

O presente trabalho busca discutir alguns processos grupais vividos a partir da experiência de trabalho da área de Psicologia Social e Comunitária da Universidade São Francisco (USF) em um projeto de extensão comunitária desenvolvido pela universidade ao longo dos anos entre 2006 e 2008. Este trabalho deu-se a partir de um projeto mais amplo da USF que foi selecionado por edital de financiamento do $\mathrm{CNPq}^{1}$. Tal seleção pública era destinada a propostas de apoio a projetos de tecnologias sociais para inclusão social de catadores de materiais recicláveis.

A partir da chamada, formou-se o grupo de trabalho para a construção do projeto, sob a coordenação do Prof. Dr. Derval dos Santos Rosa da área de engenharia. Foram envolvidas as áreas de engenharia, administração, pró-reitoria comunitária e psicologia da Universidade São Francisco. Além da universidade, foi feita uma parceria com a prefeitura municipal de Itatiba e os primeiros contatos com a cooperativa de catadores de material reciclado, a fim de fazer o convite à participação no projeto, bem como um levantamento do perfil e das demandas.

A situação inicial encontrada na cooperativa era a seguinte: ela reunia 28 cooperados (três homens e 25 mulheres), que tinham renda per capta de até $\mathrm{R} \$ 200,00$ (80\% dos cooperados); o empreendimento sofria perda de $35 \%$ do volume em massa do material coletado (sendo que o ideal seria de 5\% a 10\%); enfrentava problemas de relacionamentos interpessoais, existência de muitos conflitos no grupo, além de alta rotatividade de cooperados e de problemas de ordem administrativa e técnica.

O objetivo geral do projeto foi o de, em síntese: apoiar e fortalecer a cooperativa de catadores de materiais recicláveis, pela prática multidisciplinar, buscando agregar valor aos produtos a serem comercializados e ampliar o acesso a mercados, por meio de um empreendimento econômico solidário como política de inclusão social.

A equipe da universidade envolvia docentes e estagiários. As áreas envolvidas tinham os respectivos objetivos: Engenharia: favorecer a apropriação das tecnologias desenvolvidas (processos de seleção, lavagem e moagem), a redução do desperdício e a agregação de valor ao produto gerado. Administração: fomentar o desenvolvimento da capacidade de planejar, organizar, dirigir e controlar o negócio, melhorando as gestões financeira, fiscal e tributária. Psicologia: auxiliar o grupo a superar conflitos e dificuldades referentes a aspectos da dinâmica grupal implicada na organização do trabalho além de oferecer apoio psicossocial aos cooperados e aos seus familiares. Pró-reitoria comunitária: envolver os cooperados em uma postura cidadã e ética na organização social do trabalho, ao mesmo tempo desenvolvendo a autonomia e a independência na relação com o poder público local e com outras instituições.

No âmbito da prefeitura, foram envolvidas diferentes secretarias municipais: Obras e Meio Ambiente, Assistência Social e Educação. Desse modo, o projeto ganhava complexidade ao constituir um campo heterogêneo que incluía diferentes instituições e setores, com lógicas e funcionamentos próprios.

1 Este projeto foi financiado pelo CNPq (Edital CT-AGRO/CT-HIDRO/MCT/CNPq no 18/2005). 
É importante considerar que os editais de financiamento na área social têm enfatizado muito a metodologia participativa na construção das propostas e na execução e na gestão dos projetos. Consideramos tal perspectiva muito importante, pois muitas vezes ela define o andamento de um projeto. A inserção na comunidade em questão, o diálogo e o vínculo com ela estabelecido é um ponto nodal em todas as políticas sociais. Tal diálogo, no entanto, é bastante complexo, dado o peso das diferenças institucionais da academia, dos órgãos públicos e da comunidade no que diz respeito a objetivos, perspectivas e experiências ao longo da história.

Há de se apontar que, dentro dos limites de prazos definidos pelos editais públicos, exceto nos casos de uma relação anterior com a comunidade em questão, muitas vezes não há tempo realmente viável para a maturação de uma relação mais próxima com a comunidade para daí ser feita a construção conjunta do projeto de um modo mais satisfatório.

A USF tem uma longa tradição de projetos de extensão com a comunidade, no entanto, esta foi a primeira experiência envolvendo a área de reciclagem de material e de coleta seletiva.

Por outro lado, o trabalho multidisciplinar tem sido muito valorizado não só no discurso acadêmico, como também nas políticas públicas em geral, como forma de superar a extrema especialização dos campos do saber. No entanto, quando essa multidisciplinaridade é exigida para a execução de uma tarefa ou de um projeto, constatam-se várias dificuldades em realizá-la, tendo em vista o fato de que as diversas áreas têm bases epistemológicas muito diferenciadas, concebendo suas pesquisas e intervenções de modos diferentes. Isso leva muitas vezes a uma fragmentação do trabalho em especialidades apesar da proposta ser concebida multidisciplinarmente.

Neste caso, a proposta do projeto foi construir um trabalho efetivamente multidisciplinar, no qual cada área pudesse contribuir com sua especificidade de modo articulado com os outros atores envolvidos.

Observamos que cada área tinha claros seus objetivos, porém a dificuldade estava em como implementá-los na relação com os cooperados. Além das concepções relativas a cada área, cada profissional envolvido manifestava crenças e concepções muito singulares com relação ao grupo de cooperados.

Buscamos lidar com a diversidade de atores e de disciplinas através do diálogo constante, abrindo espaços de discussão para os diferentes pontos de vista, que envolvia em última instância diferenças de valores estruturais. Como estratégia, realizamos reuniões periódicas da equipe da universidade com cooperados e representantes da prefeitura, como também efetuamos intervenções conjuntas, onde era possível compartilhar na própria ação os diferentes saberes.

\section{A psicologia social}

A condição de marginalidade social vivida pelos catadores de material reciclável tem implicações e determinações de diversas ordens - econômicas, sociais, culturais e psíquicas. Nosso trabalho, no presente artigo, localiza-se no campo da psicologia social, pautando-se mais especificamente em uma vertente da psicanálise que compreende o sujeito como sujeito do grupo. Desse modo, as manifestações dos sujeitos estão organicamente articuladas a seu pertencimento grupal e a um âmbito social e coletivo mais amplo. Consideramos o ser humano atravessado por uma dimensão macrossocial sem perder de vista o aspecto subjetivo, a singularidade de sua história, de seu percurso pessoal. 
A psicologia social enquanto disciplina articula conhecimentos das ciências humanas, como sociologia e antropologia, com teorias psicológicas a respeito do psiquismo. São questões extremamente complexas e polêmicas que estão relacionadas à existência de uma realidade interna e outra externa, o psiquismo do sujeito e suas relações sociais.

Gonçalves Filho (1998) afirma: "Os temas da psicologia social, justamente, incidem sobre problemas intermediários, difíceis de considerar apenas pelo lado do indivíduo ou apenas pelo lado da sociedade" (p. 14).

Existe uma multideterminação na constituição do sujeito. Podemos pensar em determinantes psíquicos e determinantes sociais que se articulam em um processo complexo no qual identificamos uma existência singular, relacionada às primeiras relações objetais inscritas em uma dinâmica familiar e suas relações sociais. A articulação entre esses fenômenos deve ser realizada sem dissociá-los. Gaulejac (2001) afirma: "Se o indivíduo é o produto de uma história, esta condensa, de um lado, o conjunto dos fatores sócio-históricos que intervêm no processo de socialização e, de outro, o conjunto de fatores intrapsíquicos que determinam sua personalidade" (p. 41).

Dentre as abordagens psicanalíticas, utilizamo-nos de vertentes que vão buscar superar a dicotomia entre indivíduo e grupo, propondo uma noção de sujeito que ganha existência a partir dos vínculos intersubjetivos (Araújo \& Carreteiro, 2001; Bleger, 1992, 2001; Fernandes, 2005; Kaës, 1991, 1997, 2005a). Desse modo, a constituição do psiquismo está relacionada aos vínculos grupais, institucionais e sociais.

Para compreender a origem intersubjetiva do psiquismo, Kaës retoma em Freud a teoria do apoio, segundo a qual os conteúdos psíquicos mais primitivos derivam do apoio que a pulsão encontra sobre experiências de satisfação das necessidades corporais vitais:

A pulsão se apoia nas experiências da satisfação das necessidades corporais indispensáveis à vida; o Eu da criança se apoia na atividade psíquica do Eu materno e inicialmente no narcisismo primário da mãe; as identificações e formações do Ideal e os modelos da sublimação se apoiam em certas imposições e em certos valores coletivos socialmente organizados (Kaës, 1997, p. 98).

A partir da teoria do apoio, concebemos um psiquismo estruturado por múltiplos apoios: o corpo, o psiquismo da mãe, o grupo e sobre si mesmo e certas formações psíquicas. $O$ psiquismo se constrói através do apoio grupal e sua própria constituição estrutura-se como grupos internos, que se caracterizam como formações inconscientes do sujeito do grupo (Kaës, 1997, 2005b): imagem do corpo, imago da psique, imagos e complexos familiares, redes identificatórias, fantasias originárias.

Segundo Freud, a realidade psíquica é partilhada com outros sujeitos. Ele afirma isso a partir da investigação sobre diferentes processos: a identificação por meio do sintoma, a comunidade de fantasia, o apoio dos impulsos do Eu no Eu materno. Nesse sentido, Kaës (1997) irá desenvolver uma noção politópica do Inconsciente, apontando que este "não coincide estritamente nos seus processos de formação, nos seus conteúdos e nas suas manifestações com os limites e a lógica interna do aparelho psíquico do sujeito, considerado isoladamente" (p. 95).

O sujeito, então, constitui-se como sujeito do grupo - herdeiro, servidor e beneficiário do grupo. Seu próprio espaço intrapsíquico é estruturado em forma de grupo.

Essa maneira de conceber a constituição do sujeito vai nortear a maneira de entendermos nosso campo de estudo. Assim, conjugamos análises a respeito de dinâmicas psíquicas individuais, com as dinâmicas do grupo no qual o sujeito está inserido e com a dinâmica macrossocial do ambiente em que está envolvido. 
Desse modo, a tarefa de pesquisar a subjetividade humana deverá sempre levar em conta essas múltiplas determinações, o que equivale a dizer que, para investigarmos determinada situação, necessitaremos entender o momento histórico que vivemos, os papéis valorizados e desqualificados socialmente, as relações de trabalho, as relações afetivas e, também, a história pessoal dos sujeitos envolvidos, a história do grupo em questão, a dinâmica grupal etc. Essa é uma tarefa extremamente complexa, na medida em que essas configurações estão em constante transformação.

Outro ponto a ser considerado é que a proposta de trabalho, tal como configurada no projeto, demanda a construção de uma proximidade com os sujeitos envolvidos no campo. Tal aproximação deve basear-se em uma relação de confiança entre pesquisador e grupo, para que aquele possa conhecer de modo mais aprofundado a realidade vivida pelos sujeitos, mas também deve garantir uma distância suficiente que sustente um espaço analítico. Nesse processo, o pesquisador deve desfazer-se, na medida do possível, de seus preconceitos.

Diversos autores ligados à psicologia social apontam que há dificuldades e resistências encontradas no movimento de aproximação entre universidade e comunidade, identificando uma tendência à reprodução de relações de poder no momento dessa aproximação. No encontro entre o pesquisador e as pessoas da comunidade, é frequente presenciarmos os efeitos das diferenças sociais, que se manifestam muitas vezes em uma relação desigual e predatória (Gonçalves Filho, 1998).

$$
\text { Sluzki (1997) vai afirmar: }
$$

Das múltiplas variáveis assim chamadas macrossociais que afetam diretamente os indivíduos, a experiência social de ser pobre é particularmente marcante e desmoralizante: a experiência de indivíduos, famílias e grupos sociais submersos na pobreza é a de falta de controle sobre seu meio. Essa experiência, vale sublinhar, é co-construída por muitas das agências e instituições sociais com as quais os sujeitos interagem - já que as instituições, por meio de suas ações e procedimentos, e por meio de múltiplas interações estigmatizantes de seus representantes com os usuários, também tendem a descrever a si mesmas com o controle e o poder nas mãos, e aos indivíduos como carecendo destes (p. $65)$.

Apesar da preocupação a respeito dos cuidados necessários na aproximação entre universidade e comunidade, é frequente assistirmos discursos e análises culpabilizando e estigmatizando a população oriunda de classes menos favorecidas, imputando a elas responsabilidades que deveriam ser procuradas nas condições sociais a que foram submetidas. No cerne dessa questão está uma concepção preconceituosa a respeito da "pobreza" fruto de uma inversão ideológica na qual as causas vão ser tomadas como consequências e vice-versa.

Gaulejac (2001) alerta:

\begin{abstract}
Ao querermos responder, no plano psicológico, os problemas de gênese social, corremos o risco de aprisionarmos os indivíduos na impotência e na culpabilidade. Mas, inversamente, ao esquecermos os efeitos psíquicos das situações sociais e econômicas, deixamos de compreender por que e como os indivíduos se mobilizam ou se desmobilizam para produzir a sociedade (p. 39).
\end{abstract}

No contato com a comunidade, é importante atentar para a concepção de ser humano que permeia as ações dos pesquisadores. Em última instância, devemos estar atentos à questão das "profecias auto-realizáveis", tão comuns no encontro de sujeitos tão diferentes. Se o olhar para o sujeito já carrega desqualificação, será quase impossível que essa relação possa produzir qualquer tipo de positividade ou transformação (Montero, 2000).

Freitas (1998) aponta que a intervenção na comunidade deve ser realizada posteriormente a uma análise de necessidades, o que permitiria o estabelecimento de uma 
relação mais dialógica e horizontal. Essa análise de necessidades estaria vinculada a uma metodologia de trabalho que permitisse a aproximação com a comunidade e fosse se transformando à medida que essa relação avançasse. A escolha por metodologias de trabalho participativas visa favorecer a aproximação entre pesquisador e comunidade, em um campo dialógico no qual o contato mais próximo possa romper os preconceitos.

A participação da área de psicologia nesse projeto ofereceu a oportunidade de refletir sobre temas muito relevantes da psicologia social. Este texto expõe os diversos momentos de nossa participação.

\section{A especificidade do trabalho do psicólogo no projeto}

A partir do contato com o grupo de cooperados, constatamos diversas dificuldades no que diz respeito aos relacionamentos e à sua organização. Havia uma alta rotatividade de cooperados, bem como muitos conflitos entre eles. Para uma parte dos integrantes, o trabalho na cooperativa era visto como algo temporário enquanto não conseguiam alguma colocação melhor, como por exemplo, um emprego com carteira de trabalho assinada. A noção de cooperativismo no grupo era bastante incipiente.

A participação da área de psicologia no projeto teve como objetivo auxiliar o grupo a elaborar os conflitos e as dificuldades referentes a aspectos psíquicos da dinâmica grupal implicados na organização do trabalho, assim como oferecer apoio psicossocial aos cooperados. Atuamos no sentido de auxiliar o grupo a refletir sobre suas próprias questões, buscando construir, de um modo mais coletivo, respostas para os problemas enfrentados.

Entendemos que a especificidade do trabalho do psicólogo neste projeto está relacionada ao fortalecimento do grupo, favorecendo seu grau de dinâmica (Bleger, 1992). Essa tarefa exige uma proximidade com o grupo, através de participações regulares, bem como um trabalho mais a longo prazo.

Para realizar essa tarefa, optamos por diferentes estratégias: entrevistas individuais, grupos operativos, participação na organização das assembleias e intervenções pontuais em saúde mental (acompanhamento de alguns cooperados ou de seus familiares).

\section{As entrevistas individuais}

A fim de conhecer um pouco melhor a história de vida dos cooperados, bem como sua inserção na cooperativa, realizamos entrevistas semidirigidas com um roteiro de questões norteadoras, na quais destacamos o histórico de vida, a configuração e a dinâmica familiar, o nível de escolaridade, as experiências de trabalho, o trabalho na cooperativa e a concepção de cada um sobre o cooperativismo. As entrevistas foram realizadas na própria cooperativa e foram agendadas conforme disponibilidade de cada um. Elas foram gravadas e transcritas com autorização dos cooperados. Os depoentes participaram de forma voluntária. As entrevistas permitiram uma aproximação maior com os cooperados e um conhecimento mais profundo a respeito de suas questões pessoais. O objetivo das entrevistas não se limitou ao levantamento de informações, elas também visaram propiciar um campo de diálogo no qual o entrevistado poderia construir um espaço de reflexão acerca de sua situação de vida, delineando um universo de sentidos e de representações sobre o trabalho realizado. Foram realizadas entrevistas com oito cooperados e com a pessoa responsável pela prefeitura por acompanhar o trabalho da cooperativa. 
A partir das entrevistas, pudemos perceber que muitas pessoas estão lá por falta de outras perspectivas de trabalho: os entrevistados relatam que permanecem enquanto não surgir algo mais rentável ou enquanto for possível pagar as despesas do mês.

A quase totalidade dos entrevistados tem uma história de trabalho em que sempre existiu a figura do patrão, o que dificulta assumir um papel mais protagonista dentro do grupo. Durante toda a vida o aprendizado foi de obedecer e não manifestar opinião própria frente a superiores, o que torna a cooperativa um grande desafio.

Eles mencionam saber o que é uma cooperativa, associando-a às ideias de união e de trabalho em equipe, em que todos devem ajudar uns aos outros.

Só que tem gente que não entende o que é uma cooperativa. Eu entendo o que é uma cooperativa. Eu sei que nós temos que trabalhar se quiser produzir mais (Dona Irene) ${ }^{2}$.

[E o que a senhora acha quanto a isso, sobre o que é cooperativa?] É a gente se unir, colocar as opiniões em prática e trabalhar direitinho (Lúcia).

Nenhum dos entrevistados - exceto a presidente - demonstra um conhecimento mais aprofundado sobre cooperativismo ou mesmo sobre o funcionamento da própria cooperativa. Os cooperados mais antigos tiveram esclarecimentos sobre o tema, no entanto, não se apropriam desse espaço como um cooperado, delegando muitas vezes o conhecimento e a responsabilidade às pessoas que ocupam a presidência:

[Vocês no fim do mês, veem quanto arrecadou, tira o dinheiro da dívida que vocês estão pagando e aí divide pra todo mundo? Como que faz?] Eu acho que é isso... [A senhora não tem...] Eu não conheço os detalhes assim... [vocês não discutem isso?] A Vilma [presidente] conta, mas eu sei que tá sempre direitinho (Dona Irene).

Nas entrevistas, eles reproduzem em seus discursos uma relação de obediência com relação a figuras exteriores:

Aí ela [presidente] falou assim: - o Antônio [representante da prefeitura] decide quem vai ficar [na cooperativa] (Lúcia).

Agora há pouco, tava acabando o material... [E aí, diante disso, vocês conversam com quem? Tem alguém que tá vendo esse lado?] Tem... o Antônio ficou de ver isso pra nós... não sei se ele tá vendo, se não tá... (Júlio).

Pode ver, o Antônio nunca me viu aqui parada, nunca chamou minha atenção (...) Eu faço, sabe... o que manda eu faço, eu roço... Eu faço qualquer coisa, se manda eu limpar, eu limpo, comida eu faço... com carinho... Eu gosto daqui... Graças a Deus (Dona Irene).

Há membros do grupo que reconhecem a importância do trabalho realizado na cooperativa para a comunidade como um todo, demonstrando uma aguçada consciência ecológica. Aqueles que anteriormente trabalharam na zona rural consideram a atividade de seleção de material reciclável melhor do que o que realizavam anteriormente.

Eles também mencionam um certo preconceito por parte das pessoas com relação ao trabalho que realizam. Para alguns, isso incomoda, enquanto para outros isso não parece ser relevante: o pior é não trabalhar, depender de outros para se sustentar. Nesse sentido, também faz-se importante a sensibilização da comunidade.

Muitos, assim, acham que... Vamos falar a verdade, menosprezam o meu trabalho. Eles acham, falam que "se fosse pra mim eu não fazia um trabalho desses". No primeiro momento, eles têm preconceito, mas eu não, eu tenho orgulho do que eu faço. [Como é que você se sente quando 
as pessoas fazem isso?] No primeiro momento, a gente fica meio arrasada assim, na primeira vez, né. Depois eu falo assim: "não, eu gosto do que eu faço, porque pra você trabalhar num ambiente de reciclagem, você tem que amar muito e porque se não, você não fica, você não se adapta àquilo e... se você for ouvir o que os outros falam, você sai mesmo e acaba não ficando (Vilma).

\section{Intervenções em saúde mental}

Oferecemos aos cooperados a possibilidade de retaguarda na área de saúde mental caso houvesse a necessidade de sua parte ou de pessoas ligadas às famílias. Realizamos acolhimento psicológico e, quando necessário, encaminhamentos para a clínica escola de psicologia da universidade e para outros serviços de saúde do município, bem como orientações sobre tratamento.

Foram realizados acolhimentos com 14 cooperados. Esses acolhimentos resultaram no encaminhamento de três cooperadas e de dois familiares para atendimento psicológico e de uma cooperada para conversa no conselho tutelar e na $\mathrm{OAB}$ do município.

\section{Dos grupos operativos às assembleias}

No primeiro semestre do projeto, realizamos grupos operativos com os cooperados, cuja tarefa era discutir o trabalho realizado por eles na cooperativa. Buscamos criar um espaço em que os participantes pudessem colocar tanto as discordâncias e dificuldades, como os progressos e aprendizados.

O trabalho com o grupo de cooperados iniciou-se com reuniões de apresentação e com o estabelecimento de um contrato. Essas reuniões eram quinzenais e realizadas na sede da cooperativa, que se localiza junto ao Aterro Sanitário do município.

Conduzimos tais reuniões a partir do referencial teórico-técnico dos grupos operativos (Pichon-Rivière, 1988, 1995). Compreendemos que o grupo surge como local em que emergem e são atuados conflitos, angústias e fantasias. A técnica do grupo operativo propõe que existiriam dois níveis no discurso dos integrantes do grupo. O nível explícito e o nível implícito. Haveria sempre conteúdos inconscientes que atuariam defensivamente impedindo o crescimento do grupo. A explicitação e elaboração desses conteúdos latentes permitiriam o avançar grupal.

Nos primeiros encontros, procuramos explicitar qual era o papel da universidade, das diversas áreas envolvidas e da psicologia dentro do projeto. Percebíamos que a chegada de um grupo de pessoas estranhas, oriundas de uma classe social muito diferente causava certo malestar e muitas desconfianças no grupo de cooperados. Um silêncio constrangido estabelecia-se no grupo, alguns cooperados ficavam do lado de fora da sala, observando-nos pela janela.

Com relação aos problemas vividos na cooperativa, percebemos várias questões. A rotatividade dos cooperados era grande. Existia um grupo de mulheres mais antigas e mais estáveis na cooperativa e um grupo de integrantes novos. Percebeu-se uma dificuldade de permanência de cooperados do sexo masculino em função principalmente dos baixos rendimentos obtidos mensalmente. Em todos os grupos realizados havia ausências por desligamento e novos cooperados que haviam acabado de entrar para a cooperativa.

Trabalhamos questões sobre a relação universidade/comunidade, tentando sair da polarização saber/ignorância. Uma das estratégias para superar essa relação de poder foi a de atuar no sentido de fomentar a reflexão do grupo na construção de possíveis soluções para os problemas vividos. Uma outra estratégia foi reconhecer e potencializar algumas intervenções que apontavam para novas possibilidades de entender os problemas. 
Em um primeiro momento do grupo, a palavra ficava restrita a algumas pessoas que possuíam mais facilidade de expressão e um lugar de liderança, enquanto que o restante do grupo permanecia bastante recolhido. Percebíamos que para algumas pessoas aquele espaço se configurava como algo muito desconfortável, um espaço de impossibilidade de comunicação, marcado pela distância sociocultural. Esse espaço aberto, um lugar para dar publicidade às questões, neste primeiro momento, foi vivido como ameaçador, no qual cada colocação poderia e às vezes era seguida de retaliação.

Berstein (1989) apoiando-se nas contribuições de Pichon-Rivière, vai afirmar que existem dois medos básicos no grupo:

O primeiro é o medo de perder o que já se tem (por exemplo: os marcos referenciais prévios, benefícios secundários do sintoma, adaptações passivas a situações de enfermidades etc.). O segundo é o temor frente ao desconhecido, que pode ser perigoso, e diante do qual sentimos que não estamos preparados para manejar com a nova situação (p. 109).

Trabalhamos com eles algumas hipóteses em relação àquilo que poderia estar ocorrendo implicitamente no grupo. Abordamos as dificuldades de comunicação e os conflitos no grupo.

Percebemos que ocupar um lugar mais ativo e empreendedor era uma tarefa muito difícil para a maioria dos cooperados. O receio de se colocar no grupo também tem a ver com uma história de vida na qual sempre se ocupou lugares de ser mandado, de ter que obedecer, de ter um patrão. Muitas vezes, percebemos que o discurso da autonomia estava mais vinculado a um desejo idealizado pelos psicólogos do que algo que realmente fosse oriundo do grupo. Em diversas ocasiões, ficou muito claro o anseio pela figura de um patrão, de alguém que decidisse por eles e que "colocasse ordem" na cooperativa. A mudança de papéis não é algo fácil no grupo.

O clima durante os grupos estava sempre contaminado por um certo pessimismo e a relação entre os cooperados oscilava entre acusações, ataques e desqualificações. Havia uma impossibilidade de reconhecer as qualidades do outro que estava ligada à falta de possibilidade de reconhecer suas próprias qualidades.

Notamos uma divisão dos cooperados em dois subgrupos: os antigos e os novos integrantes. Os antigos, fundadores do grupo, falavam de um passado mítico, em que havia união, organização e trabalhava-se muito. O presente era só negatividade. Este subgrupo detinha o poder na cooperativa e, de certa forma, influenciava os novatos para atingir determinados objetivos. Já os mais novos da cooperativa questionavam o funcionamento do empreendimento e procuravam construir um lugar mais qualificado para si no grupo. Nesse processo, eles acabavam por se tornar uma ameaça aos mais antigos: as iniciativas eram tomadas como ameaça aos papéis estabelecidos.

Havia muitas dificuldades para se colocar um projeto único que irmanasse o grupo. A cisão apontada se reproduzia em diversos setores produtivos e subgrupos. Diante dos cooperados mais antigos, restava aos novatos estratégias para burlar o poder estabelecido através de fofocas e boicotes ao trabalho.

Em algumas situações, percebemos que a agressão voltava-se contra o grupo da universidade. Eram realizados ataques no sentido de questionar para que servia o grupo, que aquele espaço seria melhor aproveitado caso estivessem trabalhando, que nós não resolvíamos problema nenhum etc. Aos poucos, fomos entendendo que esse movimento acontecia nos momentos em que o grupo de cooperados se via como extremamente impotente e precisava lançar mão do ataque para se livrar da sensação de angústia. Na medida do possível, 
tentávamos discutir e elaborar essa sensação de impotência e de desqualificação, trabalhando com o grupo possíveis saídas para os impasses vividos.

É importante ressaltar que nossa intervenção partia das questões concretas e problemas cotidianos vividos pelos cooperados, a partir destes trabalhávamos as relações no grupo de cooperados, bem como deles com outras instâncias exteriores (prefeitura, compradores, vendedores, outras cooperativas).

As dificuldades de relação entre os cooperados favoreciam a ideia de que as soluções para os problemas estariam localizadas fora do grupo. Havia uma valorização das lideranças externas em detrimento das potencialidades internas. Alguns cooperados novos que se destacavam eram atacados e desqualificados, como se não houvesse espaço para outras lideranças. Todos tinham que permanecer iguais. $\mathrm{O}$ surgimento de diferenças no grupo, no sentido de membros que se sobressaíssem perante os outros gerava vários conflitos.

Podemos observar nesse momento uma predominância daquilo que Kaës denomina como polo isomórfico do grupo. Segundo o autor, a dinâmica grupal oscila entre dois polos denominados: homomórfico e isomórfico.

O polo isomórfico corresponderia ao que Freud descreveu como a massa (Kaës, 2000):

objeto comum para seus membros que implica a perda dos limites individuais, donde predominam os mesmos sentimentos, a homogeneidade mental, a exaltação e a emotividade, as reações automáticas. O polo isomórfico do aparelho psíquico grupal é efeito do processo de não diferenciação, cuja meta é reduzir ou negar a diferença entre o aparelho psíquico grupal e o espaço psíquico subjetivo. Segundo esta polaridade, só existe um espaço psíquico grupal e não espaços psíquicos individuais separados (p. 75).

Por outro lado, o polo homomórfico caracteriza-se como o momento em que "a diferenciação do espaço do aparelho psíquico grupal e do espaço do aparelho psíquico individual faz possível que a relação de cada um com o grupo possa ser elaborada" (Kaës, 2000, p. 77).

A condição para um funcionamento homomórfico é que as proibições estruturantes tenham sido enunciadas e integradas. Nesse sentido, é interessante observar que havia uma grande dificuldade em se sustentar as leis da cooperativa no grupo. A todo momento, as regras estabelecidas não eram cumpridas.

Do silêncio constrangido inicial do grupo, percebíamos uma maior participação dos cooperados, os mais antigos colocavam suas posições e os mais novos seus questionamentos. Houve momentos de grande tensão e de brigas. Alguns cooperados saíam do grupo irritados ou magoados, mas retornavam no mesmo encontro ou na semana seguinte, o que era de grande valia. Nossas intervenções eram no sentido de trabalhar, através do diálogo, esses sentimentos violentos e intensos que surgiam ameaçando o vínculo grupal. Pouco nos utilizávamos de interpretações, buscávamos mais colocar em uma outra linguagem aquilo que surgia como agressão. A ideia não era transportar diretamente um modelo psicanalítico de grupo para o trabalho com os cooperados. Esse referencial nos serviu para a compreensão de alguns fenômenos grupais e funcionava como parâmetro para construir nossas ações e posicionamentos junto ao grupo.

Uma das questões muito discutida nos grupos era a necessidade de criar-se o espaço da assembleia da cooperativa, no entanto, percebíamos uma grande dificuldade por parte dos cooperados em efetivar tal ação. A partir de discussões com os cooperados e com a equipe da universidade, resolvemos auxiliá-los na realização de suas assembleias. Nessa tarefa, por parte da universidade estariam também envolvidas as outras três áreas. 
Essa passagem do grupo operativo para a articulação com a prática concreta foi acompanhada de uma mudança do método de trabalho e do enquadre.

As reuniões passaram a ser organizadas por uma pauta que era construída no decorrer da semana pelos próprios cooperados. A cada assembleia indicava-se um coordenador e um secretário que se responsabilizariam pelo andamento dos trabalhos. No início, essa indicação era complicada, pois o grupo tinha uma tendência a sempre escolher as mesmas pessoas. Questões ligadas à desenvoltura para falar, domínio da leitura, escrita ou timidez eram alegadas para não se ocupar esses lugares.

O novo modo de funcionamento do grupo facilitou a participação, pois eram tratadas questões que diziam respeito ao dia-a-dia de trabalho e que afetavam diretamente as vidas dos cooperados.

Novamente, em um primeiro momento, instalou-se um verdadeiro campo de batalha, havendo a necessidade de se conter a raiva muito destrutiva que aparecia nos momentos de divergências. Era muito comum o grupo atacar um dos participantes, colocando-o no papel de bode expiatório (Pichon-Rivière, 1995). Essa estratégia servia muitas vezes como uma forma de o grupo não entrar em contato com suas próprias questões e contradições. Observamos ainda uma acentuada vulnerabilidade ao julgamento do outro: facilmente um gesto era traduzido como uma ofensa pessoal, gerando uma série de discussões no grupo. Podemos interpretar tal dinâmica como relacionada a falhas na função do pré-consciente, a partir das quais o não pensar ou o responder com violência evita o sofrimento de pensar as questões colocadas no vínculo de violência.

Gritar bem forte, bater, agir precipitadamente, insultar são as modalidades que colocam a vida psíquica fora do circuito e realizam a exigência de não pensar. Uma irritação lábil ou permanente engendra, em um movimento circulatório autoalimentado, o medo, a raiva, a ferida narcísica que não se cicatriza. A raiva solda um grupo que se refere somente a si mesmo e torna particularmente difícil separar-se e diferenciar-se. As funções de colocar em latência e de representar a fala ficam paralisadas ou inexistentes. Além disso, a cultura do imediatismo, com um horizonte temporal curto, mantém a excitação e orienta a descarga pulsional em direção ao acting-out (Kaës, 2005a, p. 69).

Frente a esse contexto, a vivência de temporalidade no grupo fixava-se prioritariamente à subsistência no aqui e agora, às questões emergenciais, sem dar espaço para se pensar em um projeto para a cooperativa, em sua organização a longo prazo.

Observamos que muitas vezes havia a reprodução de uma certa humilhação, muito comum nas relações patronais. Eles reproduziam entre si situações já vividas em outros lugares.

Com relação ao não cumprimento das regras internas da cooperativa, utilizamo-nos do espaço da assembleia para construir com o grupo o reconhecimento do estatuto da cooperativa e também o estabelecimento de um conjunto de regras que organizassem o trabalho cotidiano, bem como as sanções por seu não cumprimento. Tal exercício serviu para a construção de acordos grupais, aumentando a sensação de uma apropriação sobre a organização da cooperativa.

Aos poucos, começamos a perceber alguns avanços na dinâmica grupal que propiciaram a passagem do conflito sem solução para a possibilidade de um diálogo e a construção de acordos. Podemos pensar aqui na função do grupo como espaço intermediário (Kaës, 1997), que possibilita, através da construção de vínculos, um lugar de continência para os medos e as angústias.

Uma situação ocorrida na assembleia indica essa passagem. Durante uma das semanas havia acontecido um conflito entre duas cooperadas que terminou em agressão física. Esse fato foi levado à assembleia para que a decisão sobre a atitude a tomar sobre o ocorrido fosse coletiva. O grupo decidiu não expulsar as cooperadas, possibilitando mais uma chance, mas ao 
mesmo tempo criou uma regra a respeito de agressões físicas dentro da cooperativa que deveria ser cumprida a partir daquele momento. Pensamos em uma passagem do grupo como alvo de ataques para o grupo como possibilidade de cuidado.

Acompanhando essa mudança, percebemos uma legitimação cada vez maior das decisões da assembleia e uma vinculação maior com as pessoas da universidade. Houve também uma mudança no teor das pautas, que começaram a tratar mais de assuntos ligados à proteção e ao lazer dos cooperados. Os novos temas eram: passes, férias, caixa de primeiro socorros, confraternização de fim de ano, abono de falta por doença etc.

O aparecimento de aspectos mais construtivos na dinâmica grupal em contraposição aos aspectos destrutivos que predominavam, remeteu-nos a uma metáfora que envolveria o significante "lixo". Haveria uma oscilação no grupo entre a representação do lixo (inútil, sujo, indesejável) e a representação dos resíduos sólidos e material reciclável (recurso útil, cuidado ambiental).

Já apontamos no início do texto que a relação dos cooperados com o grupo de pessoas mais antigas que dirigiam a cooperativa era marcada por características de desconfiança e de boicote. Havia acusações e desqualificações de ambas as partes. Na medida em que o grupo de cooperados foi se fortalecendo por conta das reuniões nas assembleias, o tom desse conflito foi se modificando, haja vista que eles começaram a perceber o poder do grupo, inclusive para a eleição de representantes. Diversas vezes, assistimos o movimento de aparecimento de uma liderança dentro do grupo e em seguida, o afastamento dessa liderança da cooperativa. As relações de poder começavam a ficar mais explícitas, no entanto, o grupo, por medo de retaliações posteriores não conseguia sustentar a oposição.

O grau de insatisfação dos cooperados em relação aos dirigentes da cooperativa foi se agravando, havendo a perda de sua base de sustentação. No entanto, nas assembleias, observamos novamente o silenciamento de vários cooperados. A insatisfação era trazida apenas por um ou outro membro. Em uma das reuniões, interpretamos esse silêncio como o medo dos cooperados em se manifestarem e de sofrerem consequências por causa disso. A partir disso, começou a haver uma manifestação generalizada de descontentamento com relação ao modo como a diretoria estava conduzindo seu trabalho, culminando na votação da destituição da diretoria e a chamada de nova eleição em assembleia geral.

Esse processo configurou-se como um momento de crise na cooperativa, sendo vivido com muita intensidade por todos os participantes. A participação nas assembleias aumentou e vários cooperados puderam tomar a palavra e expressar suas opiniões, inclusive críticas ao modo como a equipe dirigente vinha operando. Os cooperados formaram duas chapas, construindo bases de propostas para a cooperativa e realizando debates sobre elas.

Esse processo foi muito rico em vários aspectos. O enfrentamento do instituído, o questionamento das relações de poder e a articulação de propostas para as eleições explicitaram divergências e contradições há muito tempo encobertas, ao mesmo tempo em que apontavam para saídas mais construtivas. Se, por um lado, apareciam fantasias de dissolução e de fechamento da cooperativa, por outro, percebia-se que uma nova esperança começava a ser acalentada nas falas dos cooperados. Houve um desenvolvimento do grupo e as decisões começaram a estar relacionadas com um projeto coletivo visando o futuro do empreendimento. Ao contrário de outros momentos, as discussões aconteciam sem a agressividade e a violência características, os argumentos eram colocados respeitando-se as posições dos outros. As diferenças no grupo podiam enfim ser sustentadas.

Os temas tratados nos debates sobre a eleição estavam relacionados à questão da transparência financeira e administrativa da cooperativa, da relação de respeito entre equipe dirigente e demais cooperados, à participação dos cooperados nos assuntos relativos à 
administração da cooperativa, à implantação de novos métodos de trabalho e o planejamento para o futuro.

O processo de mudança também provocou diversos tipos de resistências o que dificultou a reorganização. No entanto, as eleições aconteceram e uma nova presidente assumiu. A chapa vencedora era composta por elementos novos e antigos na cooperativa. Pela primeira vez, pôde-se observar uma certa união do grupo e um apoio da maioria à equipe dirigente. Um clima de maior confiança e de camaradagem instalou-se na cooperativa e ficava claro que o grupo estava dando um voto de confiança para a nova gestão.

Esses fatos refletem um processo de empoderamento dos cooperados e o início da percepção do funcionamento de uma verdadeira cooperativa, na qual a participação e o voto nas assembleias é o elemento central.

\section{Considerações finais}

Em nosso percurso de trabalho fomos adequando os dispositivos técnicos ao tipo de público e de problemáticas apresentadas. A passagem que realizamos da proposta de grupo operativo para a ajuda na organização das assembleias poderia, em um primeiro momento, parecer como falta de rigor metodológico no trabalho ou mesmo uma dificuldade de trabalhar com a técnica no sentido de superar resistências. Nossa análise indicou que naquele momento era necessária uma ajuda em questões concretas do cotidiano da cooperativa. Avaliamos que a mudança surtiu um efeito positivo, na medida em que deu voz a mais integrantes do grupo, aumentando o nível de participação e iniciando um questionamento a respeito das relações de poder dentro do grupo.

O grupo nos levou também a refletir sobre as relações entre os objetivos traçados pela equipe da universidade e os movimentos da cooperativa. Os conceitos de autonomia e de inclusão social, tão caros à psicologia social, esbarram em configurações psíquicas individuais e grupais que exigem uma análise mais profunda, além de colocar o paradoxo de desejar a autonomia para o outro. Estamos falando de transformações que mobilizam as alianças inconscientes colocadas no grupo.

Segundo Kaës (1997), as alianças inconscientes caracterizam-se como formações psíquicas intersubjetivas construídas pelos sujeitos de um vínculo, que sustentam formações e processos tanto do vínculo intersubjetivo como dos intrapsíquicos. São associações entre grupos de pensamentos clivados da consciência e possuem a dupla função de organização do vínculo e de defesa. Elas:

situam-se nos pontos de enlace das relações recalcadas mantidas pelos sujeitos singulares e pelos conjuntos de que são parte interessada e parte constituinte. (...) são formações da aparelhagem psíquica dos sujeitos de um conjunto intersubjetivo: casal, grupo, família, instituição. Elas determinam as modalidades do vínculo entre os sujeitos e o espaço psíquico (p. 269).

Uma hipótese possível, como anteriormente colocada, é a representação do lixo figurar como um possível organizador do vínculo grupal na cooperativa. Segundo Kaës (1997), os agrupamentos intersubjetivos se organizam como uma extensão dos grupos internos. Estes se definem como uma configuração de vínculos entre os elementos psíquicos e organizam o funcionamento do aparelho psíquico. Eles constituem a estrutura a partir da qual o sujeito transfere, enuncia-se, interpreta-se. 
Os grupos internos definem a fantasia, o sistema de relações de objeto, o Eu, a estrutura das identificações, os complexos e as imagens. Eles desempenham um papel de organizadores psíquicos inconscientes nas formações psíquicas grupais. Desse modo, o grupo intersubjetivo é uma estrutura e uma forma da realidade intrapsíquica, colocada em cena a partir de uma organização fantasmática de relações, de lugares e de ações.

Se tomarmos o objeto de trabalho da cooperativa - resíduos sólidos recicláveis podemos apreender uma representação social bastante ambivalente sobre ele, que oscila entre o lixo, o resto, aquilo que ninguém quer e o discurso ecológico de cuidado com o meio ambiente, a possibilidade de geração de renda. Observamos isso tanto na comunidade, quanto entre os próprios cooperados. Nos discursos destes últimos transpareciam tanto o orgulho de trabalhar no cuidado com o meio ambiente, como uma certa vergonha de trabalhar com o que foi descartado.

Uma de nossas hipóteses na análise do grupo é a de que o lixo e o material reciclável funcionavam como figuras de identificação no grupo e que as reações violentas e agressivas observadas surgiam principalmente quando a identificação com o lixo era mais forte. $\mathrm{Na}$ medida em que o trabalho com o grupo de cooperados avançou, a possibilidade de identificar-se com a figura do agente ambiental foi ganhando mais força.

Gostaríamos de encerrar este artigo enfatizando o fato de que o desenvolvimento das ações da área de psicologia só puderam se dar a partir da somatória e articulação com a ação dos diversos outros segmentos. Por parte da prefeitura, houve a implementação da coleta seletiva em todo o município, que era realizada por uma empresa terceirizada, juntamente com a campanha para conscientização da população sobre a importância da reciclagem do lixo.

Isso, por um lado, trouxe um relativo aumento do material coletado, mas, por outro, ao retirar os cooperados do trabalho na rua, também fez romper um vínculo importante destes com a população, que se revertia positivamente na aquisição do material. Outro efeito foi a concorrência de catadores "autônomos" que, sabendo dos horários de passagem do caminhão da coleta, antecipavam-se para pegar o material já separado pelos moradores.

Todas essas questões foram temas de várias reuniões entre a universidade, os cooperados e a prefeitura.

No que diz respeito às diferentes áreas da universidade, houve todo um trabalho feito pela área administrativa tanto no que diz respeito à organização do trabalho, como à administração financeira. A área da pró-reitoria comunitária fez diversas discussões com os cooperados sobre questões éticas e sobre a importância da sua organização política. A área de engenharia desenvolveu treinamentos com relação aos diferentes tipos de materiais que poderiam ser reciclados e também discussões sobre segurança do trabalho e implementação de equipamentos de proteção individual (EPIs).

Com a verba do projeto, foi efetuada a compra de uma máquina para moagem de plásticos, no intuito de agregar valor ao material que os cooperados separavam. Foram organizadas visitas a outras cooperativas, para que eles tivessem conhecimento da experiência de outros grupos, e incentivada a expansão dos contatos com compradores.

Com o encerramento do prazo do financiamento do $\mathrm{CNPq}$, ainda mantivemos parte das atividades junto à cooperativa. No entanto, com a saída da universidade de professores ligados ao projeto, o trabalho junto à cooperativa acabou encerrado. Antes do desligamento, organizamos o contato da cooperativa com uma incubadora de cooperativas com grande experiência na área a fim de dar continuidade à assessoria ${ }^{3}$, auxiliando o desenvolvimento do trabalho na cooperativa. Houve também uma mudança de gestão da prefeitura que implicou em alterações nas diretrizes políticas com relação à área. É importante ressaltar que, mesmo após o encerramento formal do projeto, a universidade continuou como uma referência para os 
trabalhadores da cooperativa, que solicitavam diversos tipos de ajuda, tanto nas questões mais técnicas ligadas ao trabalho propriamente dito, como na questão das relações humanas e da saúde mental.

Consideramos que o trabalho realizado junto à cooperativa de catadores de material reciclável teve avanços consideráveis, encontrou diversas dificuldades e gerou muitos aprendizados. A grande questão que nos fica é o avanço nos espaços de negociação e de diálogo em um grupo tão heterogêneo, com históricos tão diversos.

A alta rotatividade dos cooperados, a diferença de importância e o lugar que esse trabalho ocupava na vida de cada um, bem como a diversidade de visões dos diferentes atores envolvidos (cooperados, universidade e município) constituíram-se como grandes desafios no desenvolvimento de um projeto no qual as boas intenções são necessárias, mas não suficientes.

De qualquer modo, pensamos que este tipo de trabalho junto a cooperativas necessita de um longo tempo de gestão, pois, além das questões mais ligadas à racionalidade, estamos lidando com configurações psíquicas forjadas no conjunto de experiências dos sujeitos e que oscilam continuamente entre o desejo de mudança e a resistência a ela.

\section{Referências}

Araújo, J. N. G. \& Carreteiro, T. C. (Orgs.). (2001). Cenários sociais e abordagem clínica. São Paulo: Escuta.

Bernstein, M. (1989). Contribuições de Pichon-Rivière à psicoterapia de grupo. In L. C. Osório et al., Grupoterapia hoje (pp. 108-132). Porto Alegre: Artes Médicas.

Bleger, J. (1992). Psico-higiene e psicologia institucional. Porto Alegre: Artes Médicas.

Bleger, J. (2001). O grupo como instituição e o grupo nas instituições. In J. Bleger, Temas de psicologia: entrevista e grupos. São Paulo: Martins Fontes.

Fernandes, M. I. A. (2005). Mestiçagem e ideologia: algumas reflexões sobre a negatividade na construção dos laços sociais. São Paulo: Casa do Psicólogo.

Freitas, M. F. Q. (1998). Inserção na comunidade e análise de necessidades: reflexões sobre a prática do psicólogo. Psicologia: reflexão e crítica, 1 (11), 175-189.

Gaulejac, V. (2001). Psicossociologia e sociologia clínica. In T. C. Carreteiro \& J. N. G. Araújo (Orgs.), Cenários sociais e abordagem clínica (pp. 35-47). São Paulo: Escuta.

Gonçalves Filho, J. M. (1998). Humilhação social: um problema político em psicologia. Psicologia USP, 9 (2), 11-67.

Kaës, R. (1991). A instituição e as instituições: estudos psicanalíticos. São Paulo: Casa do Psicólogo.

Kaës, R. (1997). O grupo e o sujeito do grupo: elementos para uma teoria psicanalítica do grupo. São Paulo: Casa do Psicólogo.

Kaës, R. (2000). Las teorias psicoanalíticas del grupo. Amorrortu: Buenos Aires.

Kaës, R. (2005a). Os espaços psíquicos comuns e partilhados: transmissão e negatividade. São Paulo: Casa do Psicólogo.

Kaës, R. (2005b). La palabra y el vínculo: procesos asociativos em los grupos. Buenos Aires: Amorrortu.

Montero, M. (2000). Construcción, desconstrucción y crítica: teoria y sentido de la psicologia social comunitária en América Latina. In R. H. Campos \& P. A. Guareschi (Orgs.), Paradigmas em psicologia social: a perspectiva latino americana (pp. 70-87). Petrópolis: Vozes.

Pichon-Rivière, E. (1988). O processo grupal. São Paulo: Martins Fontes.

Pichon-Rivière, E. (1995). Teoria do vínculo. São Paulo: Martins Fontes. 
Singer, P. (2002). Introdução à economia solidária. São Paulo: Perseu Abramo.

Sluzki, C. E. (1997). A rede social na prática sistêmica. São Paulo: Casa do Psicólogo.

\section{Endereço para correspondência}

carlosgama@terra.com.br, mkoda@usp.br
Recebido em: 14/03/2009

Revisado em: 05/02/2010

Aprovado em: 06/02/2010 